\title{
A IMPORTÂNCIA DA ÓRTESE ESTABILIZADORA NA PREVENÇÃO DE ENTORSES DE TORNOZELO NO VOLEIBOL: UMA REVISÃO INTEGRATIVA
}

\section{Danilo Guerra Saraiva1, Carlos Eduardo Pereira de Souza², Alyne Castro de Sousa1, Giovanna Rodrigues Vieira1 ${ }^{1}$, Alaiana Marinho Franco ${ }^{2}$ and Anderson Batista Nunes ${ }^{2}$}

${ }^{1}$ Acadêmico do Curso de Graduação em Fisioterapia do Instituto de Ensino Superior do Sul do Maranhão ${ }^{2}$ Fisioterapeuta Docente do Curso de Fisioterapia do Instituto de Ensino Superior do Sul do Maranhão

\section{ARTICLE INFO}

\section{Article History:}

Received $28^{\text {th }}$ January, 2021

Received in revised form

$16^{\text {th }}$ February, 2021

Accepted $04^{\text {th }}$ March, 2021

Published online $30^{\text {th }}$ April, 2021

\section{Key Words:}

Órteses. Prevenção. Entorses. Voleibol.

*Corresponding author:

Danilo Guerra Saraiva,

\begin{abstract}
Introdução: $\mathrm{O}$ tornozelo é uma das articulações do corpo com a maior incidência de lesões no esporte, a maioria das lesões no tornozelo são por entorses em esportes de salto e que as órteses de tornozelo são equipamentos de função estabilizadora diminuindo o impacto no tornozelo após as aterrisagens. Objetivo: verificar qual a importância da órtese estabilizadora, na prevenção de entorses de tornozelo no voleibol e perceber se com o uso da mesma seria modificado o gesto esportivo do atleta. Materiais e Métodos: Nosso trabalho se caracteriza como uma revisão integrativa, realizamos a pesquisa literária nas plataformas Scielo, Pubmed e PEDro, de trabalhos publicados entre os anos de 2004 e 2020, e após incluirmos e excluirmos trabalhos de acordo com os critérios abordados, dezessete trabalhos estavam aptos a compor nossos resultados e discussão. Resultados: Encontramos que a órtese de estabilizadora de tornozelo, traz ao atleta a sensação de estabilidade, ativa a musculatura responsável por movimentos inversos ao mecanismo de lesão da entorse, além disso, limita a amplitude de movimento da inversão de tornozelo, para que a mesma não chegue ao ponto de lesão, de forma com que não altera a performance do atleta durante a pratica esportiva. Conclusão: Nesse caso, ficou claro, a exponencial importância preventiva do uso da órtese estabilizadora de tornozelo durante a prática do voleibol.
\end{abstract}

Copyright (C) 2021, Danilo Guerra Saraiva, Carlos Eduardo Pereira de Souza, Alyne Castro de Sousa, Giovanna Rodrigues Vieira, Alaiana Marinho Franco and Anderson Batista Nunes. This is an open access article distributed under the Creative Commons Attribution License, which permits unrestricted use, distribution, and reproduction in any medium, provided the original work is properly cited.

Citation: Danilo Guerra Saraiva, Carlos Eduardo Pereira de Souza, Alyne Castro de Sousa, Giovanna Rodrigues Vieira, Alaiana Marinho Franco and Anderson Batista Nunes. 2021. "A importância da órtese estabilizadora na prevenção de entorses de tornozelo no voleibol: uma revisão integrativa", International Journal of Development Research, 11, (04), 46609-46613.

\section{INTRODUÇÃO}

Segundo Tortora e Derrickson (2016), o tornozelo é a articulação que se forma a partir da junção da tíbia e fíbula, com o tálus. Dentro dessa articulação, encontra mais três articulações importantes, talocrural, subtalar e tibiofibular. A presente articulação ainda é estabilizada pelos ligamentos colaterais: medial e lateral, e ainda pela sindesmose tibiofibular. O tornozelo é a região articular onde há mais é contabilizado lesões nas atividades esportivas, tendo as entorses como a maioria dessas, sendo que, de $70 \%$ a $85 \%$ dos casos de entorse de tornozelo sendo ocasionadas pelo mecanismo de inversão. A entorse, é um movimento brusco e violento, que pode causar ruptura, estiramento dos ligamentos do tornozelo, bem como a luxação da articulação e ruptura de outros tecidos como a sindesmose (DEBIEUX, WAJNSTEJN e MANSUR, 2020).A entorse de tornozelo é baseada em uma área afetada e divide a lesão em três tipos: Estiramento ligamentar (Grau I): ocorre o estiramento dos ligamentos, mas sem que ocasione a ruptura do mesmo, causando inchaço e dor; lesão ligamentar parcial (Grau II): ocorre parcialmente a ruptura dos ligamentos e instabilidade articular causando edema, rigidez articular, dor e inchaço; lesão ligamentar total (Grau III):
Rompimento total dos ligamentos e falta de firmeza no pé ao andar. Apresenta-se dor intensa, há grande área de ruptura de vasos mostrando edema importante, hematoma de grande extensão e, ainda, tumefação na articulação do tornozelo (MARTINS et al., 2019). É observado o quadro clínico de dor com edema localizado na parte ântero-lateral do tornozelo, verifica-se equimose mais forte depois de 48 horas e dificuldade para deambular. Quanto maior a gravidade da lesão, maior as evidencias dos sinais. A união dos sintomas descritos, com o teste da gaveta anterior positivo permite a caracterização uma lesão grau 3 (ROBLES et al., 2015). No voleibol, cerca de 60\% dos atletas já sofreram lesões no tornozelo, sendo essa acometida, após o salto, quando o atleta vem a tocar o solo sozinho e "vira o pé", em inversão ou eversao, cujo este, é o mecanismo de lesão da entorse de tornozelo, a entorse pode acontecer também na aterrisagem do salto, no entanto, onde o atleta lesionado veio a pisar no dorso do pé de um atleta adversário por baixo da rede ou de um companheiro na mesma área de quadra. Onde mais se observa ocorrências dessa lesão, são no ataque e no bloqueio, justamente pela intensidade aplicada em tais movimentos e pelo mínimo contato entre atletas adversários e da mesma equipe que o voleibol possa vir a ocasionar (MARQUES JUNIOR, 2016; SANTOS, 2018; VEIGA et al., 2018). Segundo 
Kuhn et al. (2017), alguns dos meios para prevenir a entorse de tornozelo: tipos de calçados, bandagem, órteses de tornozelo e treinamento sensório-motor, dentre esses, fica em evidencia, as órteses de tornozelo, elas têm principal objetivo promover um suporte externo adicional aos ligamentos e músculos à articulação. Um utensílio muito utilizado pelos jogadores de voleibol, é a tornozeleira estabilizadora ou estabilizador articular, cerca de $68,9 \%$ dos atletas profissionais de voleibol fazem uso da tal órtese durante a prática esportiva, seja no treinamento ou na competição (MARQUES JUNIOR, 2017). Para Marques Junior (2016), o estabilizador de tornozelo, como o próprio nome afirma, aumenta a estabilidade dos movimentos do tornozelo até o pé, ocorre uma menor exigência da musculatura do tornozelo, reduzindo assim, o impacto e as forças laterais e mediais sofridas após a aterrisagem do salto. É possível afirmar, que quando utilizada na prática de voleibol, a tornozeleira estabilizadora diminui a acentuação dos movimentos articulares (inversão e eversão) os principais mecanismos de lesão para entorses de tornozelo. A órtese colabora ainda, com a diminuição do torque angular no movimento, tal fato é observado principalmente em atletas com pisada irregular, ou mesmo em uma aterrissagem inadequada de um salto. Ou seja, o utensílio reduz a gravidade da lesão ou até mesmo evita o acometimento da mesma (MORENO et al., 2016).

Existem dois tipos desses estabilizadores, o Tipo Cast e a Active Ankle T2, porém ambas são constituídas do mesmo princípio, que é um suporte que se prende sob a palmilha do tênis, posicionado com duas talas laterais, que ficarão na região distal da tíbia e fíbula e um velcro irá fechá-las, dessa forma estabilizando a articulação do tornozelo. Ambos os tipos de tornozeleiras servem para diminuir os movimentos de inversão e eversão do tornozelo no momento da aterrissagem dos saltos. A tornozeleira tipo Cast possui duas fitas enquanto a tornozeleira tipo Active Ankle T2 contém apenas uma fita, o que não altera a estabilização da articulação também não é observado queda na performance do atleta ao utilizar quaisquer tipos de estabilizadores (MARQUES JUNIOR, 2014). O presente trabalho teve o objetivo de verificar qual a importância da órtese estabilizadora articular, na prevenção de entorses de tornozelo no voleibol e perceber se com o uso da mesma seria modificado o gesto esportivo do atleta.

\section{MATERIAIS E MÉTODOS}

Desenho da Pesquisa: A presente pesquisa, se caracteriza como uma revisão integrativa, pois ocorreu uma combinação de estudos de diversas metodologias para a integração dos resultados, mantendo o rigor de uma revisão sistemática, no entanto, ampliando a possibilidade de análise de literatura, uma vez que não ocorre uma delimitação metodológica (GIL, 2017).

Pergunta Norteadora: A busca literária tem como objetivo responder a problemática que é: "Qual a importânciaestabilizador na prevenção de entorses de tornozelo no voleibol?”.

Busca na Literatura: As estratégias de busca estabelecidas foram baseadas em estudos nas línguas portuguesa, inglesa e espanhola. As fontes de busca foram Scielo, Pubmed e PEDro, publicados entre os anos de 2004 e 2020. Fora delimitado os seguintes descritores na busca por pesquisas que abrange o tema: tornozelo, anatomia e biomecânica do tornozelo, entorse de tornozelo, entorse de tornozelo no esporte, fisioterapia na entorse, tratamento fisioterapêutico em entorse, órtese de tornozelo.

Critérios de Inclusão e Exclusão: Os critérios de inclusão utilizados livros, ou trabalhos que fossem publicados em revistas, que abordassem o tema do estudo, no idioma português, espanhol e inglês, publicados entre o período de 2004 e 2020. Foram incluídos referencias de artigos selecionados nas bases de dados, desde que mantivesse a coerência com o estudo presente.Como critérios de exclusão eliminou-se trabalhos incompletos, trabalhos que possuíam outro esporte de salto, especifico na abordagem da utilização de órteses que não fosse o voleibol e trabalhos que analisaram tipos de órteses de tornozelo que não eram estabilizadores.

Seleção dos Estudos e Amostra: De início para seleção dos artigos foi realizado uma avaliação dos títulos. Em seguida, foi feita a leitura dos resumos, afim de selecionar aqueles que abordassem somente entorse de tornozelo, com estudos sobre o uso de órteses.As buscas resultaram em setenta e seis trabalhos dentre monografias, livros, artigos e revistas, onde foram selecionados trinta e quatro trabalhos, onde desses foram excluídos com motivos dezessete, por estarem dentro dos critérios de exclusão propostos no presente trabalho. Dentro do total de trabalhos, dezessete foram utilizados para consolidar os resultados e discussão, uma parte dos demais trabalhos selecionados foram utilizados para que houvesse a produção de referencial teórico e a outra parte fora descartada.

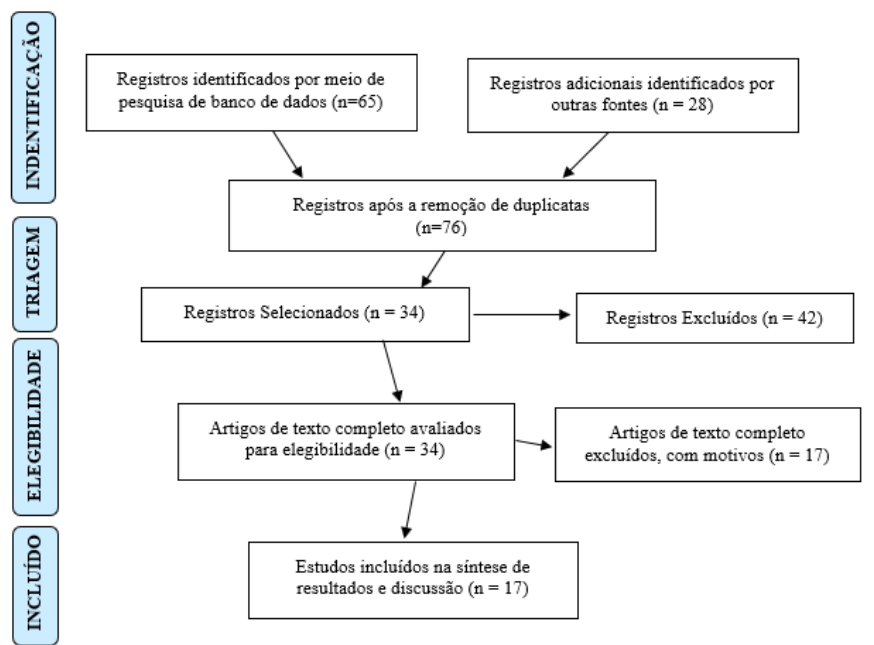

\section{RESULTADOS E DISCUSSÃO}

De acordo com os resultados da pesquisa, a órtese de estabilizadora de tornozelo, traz ao atleta a sensação de estabilidade, ativa a musculatura responsável por movimentos inversos ao mecanismo de lesão da entorse, além disso, limita a amplitude de movimento da inversão de tornozelo, para que a mesma não chegue ao ponto de lesão, de forma com que não altera a performance do atleta durante a pratica esportiva, conforme Quadro 1. Para uma excelência em prevenção de lesões, o profissional responsável deve conhecer bem o atleta, e acertar de imediato no programa preventivo, já que esse, é de suma importância para o sucesso tanto do atleta, como da equipe durante uma temporada, tendo um planejamento eficaz para que o fator preventivo venha a ser eficaz, ao se utilizar quaisquer dispositivos para essa prevenção, deve-se levar em consideração a qualidade do mesmo e o conforto que esse dispositivo venha a trazer para o atleta (RESENDE, CÂMARA e CALLEGARI, 2014). A órtese favorece o atleta que já possui, ou não, um histórico de entorses de tornozelo, no entanto, a escolha da órtese ideal para um determinado Atleta, deve ser baseada não somente quanto a proteção, mas também quanto ao seu conforto, custos e conveniência de uso. Uma vez que por maior que seja a proteção, o fator psicológico e o fator conforto, devem ser levados em consideração pra que não haja uma alteração no rendimento do atleta, mesmo não havendo nenhuma lesão (MCKEON E MATTACOLA, 2008). De acordo com Castro (2012), recomenda-se para a prevenção de lesões, o atleta fazer uso do estabilizador de tornozelo ou como popularmente é conhecido, a tornozeleira. Pois a mesma, trata à articulação do tornozelo, maior estabilidade anatômica, tendo aumentada a eficácia da tornozeleira ainda mais, quando associada a um tênis de solado baixo. É verificado que os suportes de tornozelo semi-rígidos limitam a amplitude de movimento durante intercorrências esportivas, observase ainda que os efeitos de restrição dessas órteses no movimento de inversão associado a descarga de peso é exponencialmente relevante, uma vez que mesmo com a restrição de amplitude não há perda de função no movimento, ou seja, a articulação faz o movimento até a 


\section{Quadro 1. Síntese dos estudos revisados}

\section{REFERÊNCIAS}

ZWIERS R.; VUURBERG G.; BLANKEVOORT E.; KERKHOFFSG.M.M.J. Bandagem e órtese na prevencão de entorses de tornozelo: conceitos atuais. J ISAKOS. Jt Disord Orthop Sports Med: 1(6):304-310, 2016. SIMON, J.; DONAHUE, M. Efeito da bandagem ou órtese no tornozelo na criação de um maior

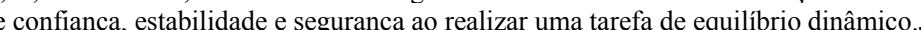
Sport Rehabil: 22 (3): 229-233, 2013 .

MARQUES JUNIOR, N.K. A importância do estabilizador para prevenir a entorse de tornozelo no jogador de voleibol: um estudo de revisão. Revista Brasileira de Prescrição e Fisiologia do Exercício, São Paulo. v.9. n.56. p.721-729. Nov./Dez. 2015.

DELAHUNT, E.; MCGRATH, U.M.A.; DORAN, N.; COUGHLAN, G.F. Efeito da bandagem na estabilidade postural dinâmica real e percebida em pessoas com instabilidade crônica do tornozelo. Arch Phys Med Rehabil.: 91(9):1383-1389, 2010.

MOLENBROEK, J.; FLEUREN, M.; RENSINK, G. Case study: external ankle sprain protection with Exo-L. Conference. 2013.

ESPOSITO, E. R.; CHOI, H. S.; OWENS, J. G.; BLANCK, R. V.; WILKEN, J. M.Biomechanical response to ankle-foot orthosis stiffness during running. Clin Biomech (Bristol, Avon),30 (10): 1125-32. Dezembro, 2015

PAPADOPOULOS, E.; NIKOLOPOULOS, C.; BADEKAS, A.; VAGENAS, G.; PAPADAKIS, S. A.; ATHANASOPOULOS, S. The effect of diferente skin-ankle brace applocations pressures on quiet single-limb balance and EMG activation onset of lower limb muscle.BMC Musculoskeletal Disordes. Vol. 7. Num. -. p. 1-8, 2007.

SHAW, M.; GRIBBLE, P.; FRYE, J. Ankle bracing, fatigue, and time to stabilization in collegiate volleyball athletes. J Athlet Train. Vol. 43. Num. 2. p. 164-71. 2008.

ALFUTH, H; KLEIN, D; KOCH, R; ROSENBAUM, D;

Comparação biomecânica de 3 órteses de tornozelo com e sem rotação livre no plano sagital. $J$ Athl Train:49 ( 5 ): 608 - 616, 2014.

OMORI L., KAWAKAMI K., SAKAMOTO M., HARA T., KOGA Y. O efeito de uma cinta de tornozelo na cinemática tridimensional e na condição de contato tíbio-talar para entorses laterais do tornozelo. Knee Surg Sports Traumatol Arthrosc: 12 ( 5 ): 457 - 462, 2004.

\section{TIPO DE ESTUDO}

Revisão Sistemática

Revisão Sistemática

Revisão Sistemática

Ensaio Clinico Randomizado

Relato de Caso

Ensaio Clinico Randomizado

Estudo Cruzado ou Crossover

Estudo de Coorte

Ensaio Comunitário
Estudo de Coorte

\section{RESULTADOS}

As órteses apresentam influências neuromusculares, o controle neuromuscular na articulação do tornozelo e ao redor dela é alcançado por meio de uma combinação de propriocepção aprimorada, atividade do músculo fibular, ação reflexiva, tempo de reação e estabilidade postural.

Os músculos fibulares são importantes eversores da articulação do tornozelo e pensados para conter os violentos momentos de inversão que normalmente ocorrem durante uma entorse do tornozelo. Há estudos que relatam um potencial benefício psicológico na estratégia de intervenção utilizando a órtese estabilizadora.

O estabilizador de tornozelo é um dispositivo adicional que contribui na estratégia de prevenção a lesões e durante a reabilitação ativa. Porém, o uso por um longo período sem estar associado as atividades esportistas e tratamento ativo, pode ser prejudicial a articulação. Os atletas que utilizam o estabilizador associado ao programa de prevenção proprioceptivo obtiveram índices menores de lesões, um resultado significativo para atletas com histórico de lesão.

$\mathrm{O}$ uso da órtese transmite percepções aprimoradas de estabilidade, confiança e tranquilidade durante a atividade e um nível de conforto que permite aos indivíduos pensar que não machucariam os tornozelos.

Foi apresentado que muitos atletas não gostam de utilizar o estabilizador com frequência porque ele é desconfortável para a prática esportiva. Ambos realizarem um estudo e apresentaram um gráfico sobre a relação entre grau de proteção e conforto para a prática esportiva.Quanto mais alto na vertical o estabilizador, mais confortável é o equipamento, e quanto mais largo na horizontal, mais o equipamento protege o tornozelo do atleta.

$\mathrm{O}$ estabilizador de tornozelo não atrapalha o desempenho de um atleta, conforme, a rigidez da articulação do tornozelo foi maior na haste mais rígida e menor na haste flexível, porém o trabalho mecânico do tornozelo permaneceu inalterado, Velocidade, comprimento da passada, tempo de ciclo, ângulos articulares, momentos, potências e forças de reação do solo não foram significativamente diferentes entre as condições de estabilização da órtese e articulação desprotegida. Foi mensurado na eletromiografia (EMG) a ativação dos músculos dos membros inferiores do indivíduo quando executa um passo para frente, sendo detectado nos sujeitos que participaram do estudo que, equipamento, concluindo que, o estabilizador previne contra a lesão e ajuda na performance porque os músculos do tornozelo são menos exigidos.

Jovens jogadoras de voleibol na quadra, onde foram induzidas a entrar em fadiga praticando vários testes (saltos, agilidade, lunge e equilíbrio), após isso foi mensurado o tempo da estabilização do tornozelo.Entende-se que a fadiga ocasiona instabilidade no tornozelo do praticante do esporte e da atividade física, por conta da exigência da musculatura e articulação, proporciona mais chance de lesão nessa região anatômica. Este estudo mostrou que o estabilizador ocasiona uma estabilização mais breve quando comparado sem esse acessório.Os resultados das jogadoras de voleibol com fadiga na estabilização anterior e posterior do tornozelo foi o seguinte: 3,341, ou seja, 0,339 segundos sem equipamento e 2,492, ou seja, 0,271 segundos com estabilizador.Enquanto os resultados da estabilização medial e lateral do tornozelo os valores foram os seguintes: 1,360 , ou seja, 0,077 segundos sem equipmento e 1,257, ou seja, 0,016 segundos com estabilizador ( $\mathrm{p}>0,05)$. Em conclusa 0 , o estabilizador o importante durante a pratica do tornozelo que o sistema neuromotor, podendo prevenir o jogador de uma lesão nessa articulação.

Concluíram em seu estudo que, as órteses de tornozelo controlaram com sucesso a amplitude de movimento em inversão passiva e flexão plantar.

Foi descrito sem a órtese um aumento da rotação interna e de inversão após a transecção dos ligamentos laterais, enquanto a aplicação de uma órtese específica não mostrou alteração da rotação interna, determinando a restrição do movimento com o uso. 
amplitude máxima, sendo impedida pela órtese de chegar a uma amplitude lesiva (SILVA E GONÇALVES, 2007). Os benefícios da órtese estabilizadora de tornozelo vão além do benefício de estabilização mecânica, há evidências de alterações eletromiográficas com o uso da órtese estabilizadora de tornozelo, como um aumento da ativação muscular de fibular curto e fibular longo, que são músculos que possuem como propriedade de ação, a realização da eversão, que é o movimento contrário ao movimento mais comum em entorses de tornozelo. (MILANEZI, 2014). A utilização da órtese estabilizadora de tornozelo por atletas voleibolistas profissionais, não acarreta nenhuma alteração de rendimento durante o movimento de salto vertical, equilibro e agilidade, que são os gestos esportivos do voleibol, em relação a indivíduos que não fazem uso da mesma, mostrando que a utilização da tornozeleira, não interfere no rendimento do atleta durante o ato competitivo (ANJOS et al., 2009; AGUIAR e MEJIA, 2012).

\section{CONCLUSÃO}

Após a realização dos resultados e discussão, fica evidenciado que: A prevenção de lesões, não somente no voleibol, como no esporte de alto rendimento em geral, é um fator imprescindível, uma vez que, o advento de um atleta de alto rendimento ficar fora de uma partida ou competição, acarreta prejuízos para o rendimento da equipe durante toda uma temporada. No entanto, fica claro ainda que tal prevenção, terá efetividade, somente com um planejamento acertado da equipe multidisciplinar que estará engajada em tal causa. É observado que tanto na modalidade voleibol, bem como nas demais modalidades esportivas de alto rendimento, o tornozelo é uma articulação bastante acometida, uma vez que, é uma área que durante a prática esportiva tem sua instabilidade elevada, no voleibol, ainda, é uma articulação bastante exposta aos choques e contatos entre atletas, o que aumenta a instabilidade e consequentemente gera a entorse. Nesse caso, fica claro a exponencial importância preventiva do uso da órtese estabilizadora de tornozelo durante a prática esportiva, principalmente o voleibol, uma vez que, a mesma, tem benefícios mecânicos, como a limitação da amplitude de movimento durante intercorrências na prática esportiva, bem como, as constatadas alterações eletromiográficas de aumento de ativação muscular, em músculos que são fundamentais para que não haja a entorse de tornozelo. E ainda, a utilização da tornozeleira, não traz alteração ao rendimento do atleta profissional de voleibol durante a competição, fato este, que corrobora com os resultados encontrados. As órteses de tornozelo que já são utilizadas na pratica profissional do voleibol, são contundentemente eficazes na prevenção de entorses tornozelo de atletas de alto rendimento. $\mathrm{O}$ dispositivo de suporte não altera $\mathrm{o}$ mecanismo de lesão, mas sim, atua diminuindo a acentuação do grau desse mecanismo, fazendo com que não chegue a um grau lesivo, bem como reduz a sua intensidade, além de participarem da redução da amplitude do movimento que favorece a lesão, ainda, ativam a musculatura que faz o movimento contrário ao movimento lesivo. Outro ponto fundamental, é o fato de que a utilização da órtese estabilizadora de tornozelo, não altera em nenhum ponto do gesto esportivo, a performance do atleta, atuando apenas como um utensílio de prevenção de entorses.

\section{REFERENCES}

Aguiar, D. R.; Mejia, D. P. M. 2012. A interferência do uso da órtese e a da bandagem no desempenho esportivo de indivíduos com instabilidade de tornozelo: uma revisão integrativa. Biocursos.

Alfuth, H; Klein, D; Koch, R; Rosenbaum, D. 2014. Comparação biomecânica de 3 órteses de tornozelo com e sem rotação livre no plano sagital. J Athl Train: 49 ( 5 ): $608-616$.

Anjos, M. T. S. Brasil, L. J.; Barros, B. O.; Bastos, N. C. S.; Moraes, G. F. S. 2009.Efeito do Uso do Estabilizador Active Ankle System ${ }^{\circledR}$ na Altura do Salto Vertical em Jogadores de Voleibol. Rev Bras Med Esporte, v. 15, n. 5, p. 347-350, Niterói-RJ.
Castro, L. M.2012. Principais Lesões Articulares na Modalidade Voleibol. Orientador: Prof. Dr. Fabiano de Barros Souza. 2012. 31 f. Trabalho de Conclusão de Curso (Bacharelado em Educação Física) - Universidade do Vale do Paraíba, Jacareí-SP.

Debieux, P; Wajnsztejn, A; Mansur, N.S.B. 2020.Epidemiologia das lesões por entorse do tornozelo diagnosticadas em pronto atendimento de ortopedia. Rev. Einstein São Paulo. 18:1-6.

Delahunt, E.; Mcgrath, U.M.A.; Doran, N.; Coughlan, G.F. 2010.Efeito da bandagem na estabilidade postural dinâmica real e percebida em pessoas com instabilidade crônica do tornozelo. Arch Phys Med Rehabil.: 91(9):1383-1389.

Esposito, E. R.; Choi, H. S.; Owens, J. G.; Blanck, R. V.; Wilken, J. M.2015.Biomechanical response to ankle-foot orthosis stiffness during running. Clin Biomech (Bristol, Avon), 30 (10): 1125-32. Dezembro.

Gil, A. C. 2017.Como Elaborar Projetos de Pesquisa 6. ed. São Paulo: Atlas.

Kuhn, B.; Nazzi, N. B.; Oliveira, M.; Moussalle, M. M.; Soares, M.M. 2017.A Estabilidade Do Tornozelo Em Atletas Do Voleibol Masculino. Revista Conhecimento Online, v. 1, p. 5964.

Marques Júnior, N. K. 2015. A importância do estabilizador para prevenir a entorse de tornozelo no jogador de voleibol: um estudo de revisão. Revista Brasileira de Prescrição e Fisiologia do Exercício, São Paulo. v.9. n.56. p.721-729. Nov./Dez.

Marques Júnior, N. K.2014. Equipamento recomendado para proteger o voleibolista durante o jogo de voleibol. Lecturas: Educ Fís Dep. Vol. 19. Num. 192. p. 1-13.

Marques Júnior, N. K.2016. Análise cinesiológica dos fundamentos do voleibol: conteúdo para prescrever o treino neuromuscularforça e flexibilidade. Revista Brasileira de Prescrição e Fisiologia do Exercício (RBPFEX), v. 10, n. 57, p. 155-191.

Marques Júnior, N. K.2017. Efeito do Estabilizador de tornozelo no joelho do atleta de voleibol: um estudo de revisão. Revista Brasileira de Prescrição e Fisiologia do Exercício, São Paulo. v.11. n.66. p.386-395. Maio/Jun.

Martins, E. B. O.; Ramão, G. R.; Kubo, M. H. S.; Zilch, T. R.; Lima, M. C.; Perpétuo, F. L. 2019.Impacto do Treino Proprioceptivo na Prevenção em Lesões de Atletas de Basquetebol. Edição Especial Projetos Integradores. Pleiade, 13(27): 90-102, Mar.

Mckeon, P. O.; Mattacola, C. G.2008. Interventions for the Prevention of First Time and Recurrent Ankle Sprains. Clin. Sports Med., v. 27, p. 371-382.

Milanezi, F. C.2014. Análise da Estabilidade do Tornozelo em Movimentos Esportivos e o Efeito da Órtese Semi-Rígida. Orientador: Prof. Dr. Adalgiso Coscrato Cardozo. 2014. 83 F. Dissertação (Mestrado em Desenvolvimento Humano e Tecnologias) - Universidade Estadual Paulista, Rio Claro-SP.

Molenbroek, J.; Fleuren, M.; Rensink, G.2013. Case study: external ankle sprain protection with Exo-L. Conference.

Moreno, J.; Afonso, J.; Mesquita, I.; Ureña, A. 2016.Dynamics between playing activities and rest time in high level men`s volleyball. Int J Perf Analysis port. Vol. 16. Num. 1. p.317-31.

Omori, L.; Kawakami, K.; Sakamoto, M.; Hara, T.; Koga, Y. 2004.O efeito de uma cinta de tornozelo na cinemática tridimensional e na condição de contato tíbio-talar para entorses laterais do tornozelo. Knee Surg Sports Traumatol Arthrosc: 12 ( 5 ): 457 462 .

Papadopoulos, E.; Nikolopoulos, C.; Badekas, A.; Vagenas, G.; Papadakis, S. A.; Athanasopoulos, S. 2007.The effect of diferente skin-ankle brace applocations pressures on quiet single-limb balance and EMG activation onset of lower limb muscle. BMC Musculoskeletal Disordes. Vol. 7. Num. -. p. 1-8.

Resende, M. M.; Câmara, C. N. S.; Callegari, B.2014. Fisioterapia e prevenção de lesões esportivas. Fisioterapia Brasil, volume 15, número 3

Robles, D. S.;Esteves, S.; Martins, S.; Ferreira, N.; Marinheiro. J.; Sousa, C. 2015.Dor persistente após entorse do tornozelo: um caso clínico de sinostose do ligamento tíbio-peroneal anterior distal. Rev. Port. Ortop. Traum., Lisboa, v. 23, n. 3, p. $257-$ 264. 
Santos, A.L. 2018.Incidência de entorse de tornozelo em atletas amadores de duas equipes de voleibol da grande Florianópolis. Universidade do Sul de Santa Catarina - UNISUL.

Shaw, M.; Gribble, P.; Frye, J. 2008. Ankle bracing, fatigue, and time to stabilization in collegiate volleyball athletes. J Athlet Train. Vol. 43. Num. 2. p. 164-71.

Silva, P. B.; Gonçalves, M. 2007.Suportes de pé e tornozelo: efeitos na biomecânica e na prevenção de lesões desportivas. Motriz. Rio Claro, v. 13, no 4, p. 312-323, out./dez.

Simon, J.; Donahue, M.2013. Efeito da bandagem ou órtese no tornozelo na criação de um maior senso de confiança, estabilidade e segurança ao realizar uma tarefa de equilíbrio dinâmico. J Sport Rehabil: 22 (3): 229-233.
Tortora, G. J.; Derrickson, B. 2016. Princípios de Anatomia e fisiologia. 14. ed. Rio de Janeiro: Guanabara Koogan.

Veiga, A. M.; Souza, G. G; Keller, K. D. A. 2018. biomecânica do vôlei e a entorse de tornozelo: uma revisão de literatura. XXIII Seminário interinstitucional de Ensino, Pesquisa e Extensão. UNICRUZ. Cruz Alta - RS.

Zwiers, R.; Vuurberg, G.; Blankevoort, E.; Kerkhoffs,G. M. M. J. 2016. Bandagem e órtese na prevenção de entorses de tornozelo: conceitos atuais. J ISAKOS. Jt Disord Orthop Sports Med: 1(6):304-310 . 